\title{
Spatial Market Efficiency and Policy Regime Change: Seemingly UnRelated Error Correction Model Estimation
}

\author{
Stanley R. Thompson, Donggyu Sul, And Martin T. Bohl
}

\begin{abstract}
We investigate the degree to which the wheat markets of France, Germany, and the United Kingdom are in spatial equilibrium and how reforms to the CAP affect the speed of convergence to the longrun relationship. Due to the interrelationship among these markets and the nonstationarity of our data we introduce a seemingly unrelated regression-augmented Dickey-Fuller and error correction methodology. We argue this methodology is more efficient than ordinary cointegration and error correction models. Empirically we find strong evidence of efficient spatial markets and conformity to the law of one price. Market liberalization reforms in the EU increased the comovement of domestic and world wheat prices; our post-Uruguay Round price transmission elasticity was 0.183 .
\end{abstract}

Key words: error correction model, law of one price, policy regime change, spatial market equilibrium.

The degree to which markets are spatially efficient has important implications for market liberalization and other policy reform. How these reforms alter the convergence of international prices is of major interest to policy makers. Do policy reforms indeed affect the degree to which international price signals are transmitted to within-country markets and, if so, what is the nature of this relationship?

The importance of these and other questions has led to a number of empirical tests for the existence of the law of one price (LOP) and related measures of market integration and efficiency (Fackler and Goodwin). ${ }^{1}$ These contributions emphasize the need to use econometric procedures appropriate for nonstationary

Stanley R. Thompson is a professor in the Department of Agricultural, Environmental, and Development Economics at Ohio State University; Donggyu Sul is a senior lecturer in the Department of Economics at University of Auckland; and Martin T. Bohl is a professor in the Department of Economics, European University Viadrina Frankfurt (Oder). Senior authorship is not assigned.

The authors are indebted to Professor Dr. Roland Herrmann, Institute for Agricultural Policy and Market Research, University of Giessen, Germany, Christopher Barrett and two anonymous referees for their helpful suggestions and comments. We also thank Garry Mahon, eurostat, European Commision, for the provision of data. Financial support was provided by The Ohio Agricultural Research and Development Center and the Deutsche Forschungsgemeinschaft.

${ }^{1}$ According to Fackler and Goodwin, universally accepted definitions of market integration and spatial market efficiency do not exist. Markets are considered to be integrated (to some extent) if trade actually or potentially occurs. Market integration is a quantity-based indicator of tradability, while efficiency is a pricebased indicator. In this article, we adopt the price-based notion of efficiency based on economic concepts of equilibrium (Barrett). and cointegrated data series. The recent literature has focused on the influence of transactions costs, seasonality, and threshold effects on tests for market integration (Ardini, Baffes, Blauch, Goodwin and Piggott, McNew and Fackler, Zanias). Although the findings are generally mixed, a number of investigators have found evidence for integrated commodity markets. However, in cases where LOP tests have failed, speculation is often directed to sample specific concerns, exchange rate risk, the existence of market distortions or inappropriate estimation procedures (Miljkovic). The focus of our article is on the choice of estimation technique and the extent to which liberalizing policy reforms contribute to spatial market efficiency. In particular, we provide evidence of whether European wheat markets are in spatial equilibrium, and how reforms to the Common Agricultural Policy (CAP) impact the speed of adjustment to the long-run relationship.

We introduce an econometric procedure that is more efficient than ordinary methods when panel data are used. Specifically, for markets that bear a close conceptual relationship with one another, we present a seemingly unrelated regression methodology to account for cross-equation statistical correlations among markets. We exploit information contained in the residual variance-covariance matrix to improve the efficiency of the statistical estimates. Panel data are used to investigate empirically 
the price relationships among three European Union (EU) wheat markets, namely France, Germany, and the United Kingdom. In this case, the CAP provides the policy umbrella for all three countries.

First, we test for the LOP using an iterative seemingly unrelated regression-augmented Dickey-Fuller (SURADF) test. Second, we assess the short-run dynamics with a seemingly unrelated regression error correction model (SURECM). Comparisons are made with ordinary augmented Dickey-Fuller (ADF) and error correction model (ECM) estimates; we find the empirical differences to be remarkable. Third, we investigate the impact of policy regime change on tests for spatial market equilibrium. An examination of the stochastic properties of quarterly prices for wheat over a period of significant policy change in three EU countries yields our empirical evidence.

The next two sections describe the analytical model, the data series, and the EU policy environment. Following the presentation of the methodology and the empirical findings, we provide some concluding remarks.

\section{Analytical Model}

According to the LOP, at a given point in time, the domestic commodity price should equal its world price, after adjustments are made for exchange rates, policy effects, transportation and other transactions costs, and product quality differences (Mundlak and Larson). ${ }^{2}$ Efficient commodity arbitrage will lead to an equilibrium where domestic and world prices will differ by no more than the cost of arbitrage. Hence, for a given homogenous commodity, the deviation from the LOP can be written in logarithms as

$$
p_{i t}^{d}-s_{i t}-p_{t}^{w}=\tau_{t}+\eta_{t}+\xi_{t}
$$

where $p_{i t}^{d}$ denotes the logarithm of the wheat price of the $i$ th country, $s_{i t}$ the logarithm of the exchange rate of country $i$ 's currency price per US\$, and $p_{t}^{w}$ the logarithm of the world wheat price (in US\$). The sources of the deviation from the LOP consist of the logarithm of transaction costs $\tau_{t}$, policy effects $\eta_{t}$, and product quality differences $\xi_{t}$. If one of these

\footnotetext{
${ }^{2}$ In our empirical illustrations, we account explicitly for currency exchange rates, policy regime changes, and transportation costs (border prices). Moreover, since we believe that the cost of arranging transactions has neither increased nor fluctuated greatly over time, other transactions costs are considered stationary.
}

terms is not stationary, the LOP does not hold in the long run. For example, when the logarithm of transaction costs are not stationary, the deviation from the LOP simply becomes a nonstationary variable even though $\eta_{t}$ and $\xi_{t}$ are stationary.

Lack of empirical evidence for the LOP has often been attributed to the poor power of unit root tests. Conventional unit root tests suffer from lack of power especially in the presence of breaks or regime shifts. Recently, a number of studies have employed threshold-type regressions to achieve more favorable LOP results, and to reflect a more realistic environment (Goodwin and Piggott). However, it cannot be ruled out that threshold regressions also suffer from low test power as well as size distortion. As an alternative, we consider the SURADF test as well as the panel ADF test under the assumption of the unique long-run relationship in equation (1). Moreover, we design a seemingly unrelated error correction model and a panel error correction model in order to obtain rich short-run dynamics in the presence of several breaks in the deviation from the longrun equilibrium LOP. Given possible breaks in the equilibrium error structure, panel or SUR threshold regression would be appropriate; however, this methodology is beyond the scope of this article.

To test the long-run relationship (1), we consider the following regression with logtransformed data

$$
\begin{aligned}
\Delta q_{i t}= & a_{i}+\left(\rho_{i}-1\right) q_{i t-1} \\
& +\sum_{j=1}^{k_{j}} \delta_{i j} \Delta q_{i t-j}+\varepsilon_{i t}
\end{aligned}
$$

where $q_{i t}=p_{i t}^{d s}-p_{t}^{w}$ with the logarithm of the domestic wheat price in terms of the US\$ $p_{i t}^{d s}=p_{i t}^{d}-s_{i t}, a_{i}$ is an individual-specific effect which allows us to account for initial price differences among countries, and $\varepsilon_{i t}$ is correlated with $\varepsilon_{j t}$. SURADF tests reflect the cross movements of the regression residuals. In other words, the comovements of the deviation from the LOP in the panel of countries contribute to a more powerful test. ${ }^{3}$ The LOP holds in the long run if all $\left|\rho_{i}\right|$ 's are less than one. ${ }^{4}$

\footnotetext{
${ }^{3}$ Recently, a number of panel unit root tests have been proposed which all rely on the assumption of cross-sectional independence. Under the presence of cross-sectional dependence, asymptotic distributions of test statistics become unknown. In SURADF tests, however, these problems do not exist.

${ }^{4}$ Abuaf and Jorion assume a homogenous convergence rate (i.e. $\rho_{i}=\rho$ ), while $\mathrm{Wu}$ relaxes this strong restriction and considers
} 
Equation (2) is a strong form of LOP, and it is assumed that there is only one long-run relationship between the logarithm of the two wheat price time series with the cointegrating parameter -1 ; that is, the logarithm of exchange rate-adjusted domestic wheat prices and the world wheat prices are cointegrated with the cointegrating vector $(1,-1)$. It is worth noting that the stationarity of $q_{i t}$ does not necessarily imply perfect market integration. If $q_{i t}$ is nonstationary, then it simply indicates that the two markets are totally separated.

According to the Granger representation theorem (Engle and Granger), cointegration between time series implies a valid error correction representation in which the changes in each variable are regressed on a constant, $\left(k_{j}-1\right)$ lags of the variable's own changes, $\left(l_{j}-1\right)$ lags of changes in the other variable as well as the lagged level of the error correction term $q_{i t-1}$. The lagged changes in the variables capture the short-run dynamics and the lagged error correction term contains the long-run information. All variables of an ECM exhibit the property of stationarity under the condition that the levels of the individual variables are integrated of order one and a cointegrating relationship between the variables exists. Statistical significance of the error correction parameter implies in turn the existence of a cointegrating relationship.

We consider an ECM under the assumption that $q_{i t}$ is stationary to evaluate the degree of spatial market efficiency:

$$
\begin{aligned}
\Delta p_{i t}^{d s}= & \mu_{0 i}+\lambda_{0 i} q_{i t-1}+\sum_{j=1}^{k_{j}} b 1_{i j} \Delta p_{i t-j}^{d s} \\
& +\sum_{j=1}^{l_{j}} b 2_{i j} \Delta p_{t-j}^{w}+e 1_{i t} \\
\Delta p_{t}^{w}= & \mu_{1 i}+\lambda_{1 i} q_{i t-1}+\sum_{j=1}^{k_{j}} c 1_{i j} \Delta p_{i t-j}^{d s} \\
& +\sum_{j=1}^{l_{j}} c 2_{i j} \Delta p_{t-j}^{w}+e 2_{i t} .
\end{aligned}
$$

This two-equation system assumes that the long-run relationship between the domestic and the world wheat price should be unique,

heterogenous convergence rates. As Breuer, McNown, and Wallace point out, the assumption of heterogenous convergence rates enables either joint or separate testing of unit roots. but the short-run relationship between the two markets may vary according to government policies, regulations, transaction costs, and the like. ${ }^{5}$ The point estimates of $\lambda$ have important economic content. First, the stationarity of $q_{i t}$ requires $\lambda_{0 i} \leq 0$ and $\lambda_{1 i} \geq 0$. Second, the weak exogeneity of the world wheat price with respect to the long-run parameters in the LOP relationship requires $\lambda_{1 i}=0$, so the deviation from LOP, $q_{i t}$, does not affect the world wheat price. ${ }^{6}$ Third, the point estimates of $\lambda_{0 i}$, measure the speed of adjustment to the longrun equilibrium, that is the $\lambda_{0 i} \mathrm{~s}$ measure how much $p_{i t}^{d s}$ responds to a deviation from the long-run equilibrium in the previous period. The larger the absolute values of $\lambda_{0 i}$, the faster the convergence of the deviation toward LOP. Fourth, relying on the $\lambda_{0 i}$ estimates the halflife of convergence can be computed. Fifth, the estimated error correction coefficient $\lambda_{0 i}$ in equation (3) is a proxy for the short-run transmission elasticity. ${ }^{7}$

\section{The Data and EU Policy Environment}

Twenty-four years of quarterly domestic and world (border) price data (1976:II-1999:IV) were used. Domestic producer level prices (national currency) for soft wheat in France, Germany, and the United Kingdom were obtained from the CRONOS data bank of EUROSTAT. World wheat prices CIF Rotterdam (US\$), were obtained from various U.S. Department of Agriculture publications. ${ }^{8}$ Currency exchange rates from the IMF's International Financial Statistics were used to convert the local price to U.S. currency. ${ }^{9}$ All

\footnotetext{
${ }^{5}$ By setting $l_{j}=1$ in equation (3) and $k_{j}=1$ in equation (4) we avoid contemporaneous problems which would arise by including the respective current variables $\Delta p_{t}^{w}$ and $\Delta p_{i t}^{d s}$.

${ }^{6}$ Weak exogeneity does not imply Granger causality since in an error correction framework Granger causality involves tests of statistical significance on the coefficients of the lagged terms $\Delta p_{i t}^{d s}$ and $\Delta p_{t}^{w}$ in addition to the parameters of the error correction terms $q_{i t-1}$ in equations (3) and (4).

${ }^{7}$ In discrete time-series data, the $k$ th horizon price transmission elasticity from $p_{t}^{w}$ to $p_{t}^{d s}$ is defined as $e_{P}^{d s}=\left[\Delta p_{t+k}^{d s} / p_{t}^{d s}\right] /$ $\left[\Delta p_{t+k}^{w} / p_{t}^{w}\right]$. This concept is captured by the so-called impulseresponse function given by $\partial p_{t+k}^{d s} / \partial e j_{t}$. It described the response of $p_{t+k}^{d s}$ to a one-time impulse in $e j_{t}$. For $k=1, \lambda_{0}$ captures this effect. Meanwhile, the long-run price transmission elasticity is measured by the cointegrating vector since a permanent change in $p^{d s}$ due to the change of $p^{w}$ in the long run must be the cointegrating vector.

${ }^{8}$ The CIF Rotterdam prices do not include variable import levies or tariffs. Since the world wheat price is CIF Rotterdam, ocean freight costs are not an issue since all prices are EU-based.

${ }^{9}$ The nominal price series were deflated by the quarterly consumer prices indices for France, Germany, the United Kingdom and the United States. Statistical tests (not presented) showed no
} 


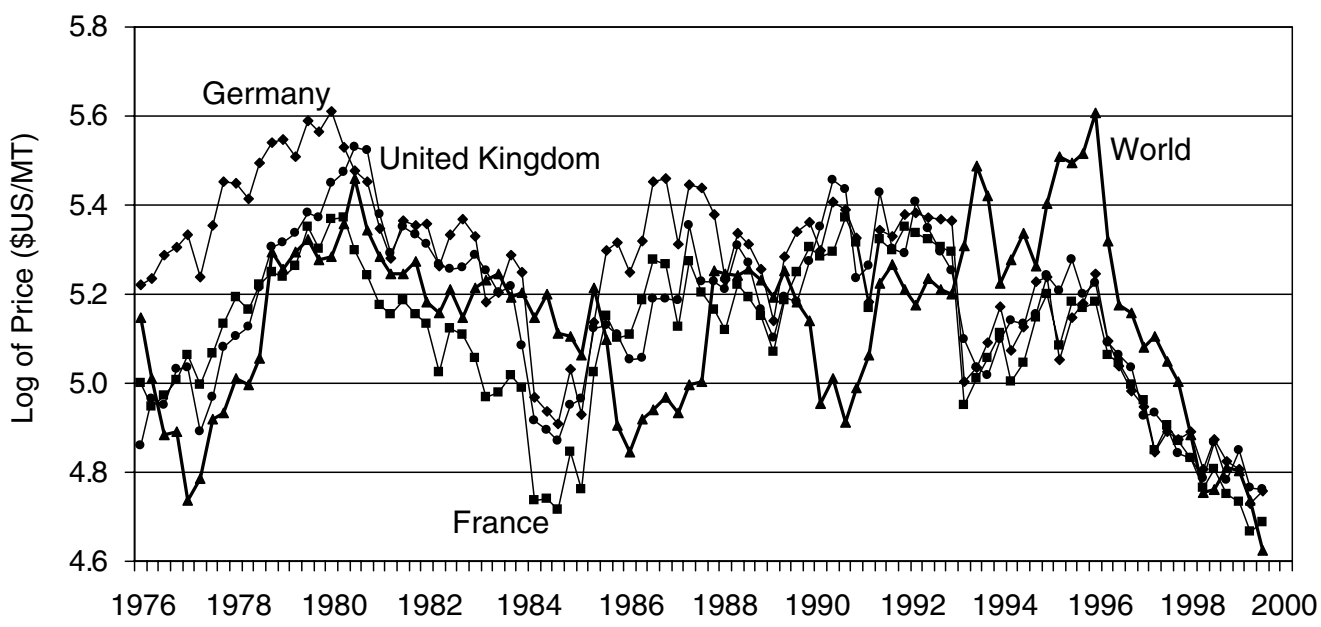

Figure 1. European and world wheat prices (\$US/MT)

price data in our empirical analysis are in U.S. currency. ${ }^{10}$

We do not have reliable data on the costs of arranging transactions; thus, we make the strong assumption that the transactions costs not included in freight costs or policy regime changes are stationary. Only border price data adjusted for currency exchange rates and changes in policy regimes are available. We have controlled for the key factors; all of the components of $\tau_{t}$ and $\xi_{t}$ in equation (1) are simply not available. Our analysis falls into what Barrett has termed a level II method of market analysis, which "... closely resembles spatial equilibrium theory" (Barrett).

Figure 1 displays the movements of the log of domestic and world prices. Visual inspection reveals that the movements of EU wheat prices are very similar and the three series seem to converge toward the end of the sample. Based on these price relationships, we suspect high cross-sectional correlation among the three

discernible difference between the deflated and undeflated series. Hence, nominal prices were selected for analysis.

${ }^{10}$ Due to the possibility of nonstationary seasonal components, we do not use any seasonal adjustment. Any treatment for seasonality results in an overlapping sampling problem and accurate subsample analysis requires non-overlapping information. Moreover, with nonseasonal adjusted monthly data, the empirical results are extremely sensitive to the choice of the lag length. Consequently, nonseasonal adjusted quarterly data are used to obtain robust estimation results. Following the argument put forward by Hakkio and Rush we do not expect major changes in our conclusions concerning the long-run investigation. However, relying on quarterly rather than monthly data we cannot rule out differences with respect to the short-run implications due to a higher information content of monthly time series. See von Cramon-Taubadel, Loy, and Musfeldt for empirical evidence on this issue.
European wheat price time series. The extent to which they are related to each other and the world wheat price as well as how their relationship is impacted by policy change is presented below.

Figure 2 shows the movements of the $\log$ deviation from LOP for the individual countries, $q_{i t}, i=1,2,3$, and the log average deviation from LOP, $\Sigma_{i=1}^{3} q_{i t} / 3$.0. If either transaction costs or policy effects have regime shifts, the deviation from LOP should also shift. However, it is hard to visually detect these regime shifts in figure 2 . Thus, if the number of the breaks and breakpoints are not known, it makes little sense to implement thresholdtype tests.

Before we discuss our estimation procedures and results, we review the evolution of CAP policy and identify policy regime subperiods corresponding to points of major policy change. Our empirical analysis will take explicit account of the impact of these regime periods on the international transmission of world prices to European wheat markets.

We characterize agricultural policy in the EU from 1976 through 1992 as the "old CAP"; a highly managed market system of administratively determined prices and protectionist policies. Since during most of this period the EU was surplus in wheat, intervention buying was the key mechanism to support internal prices above world levels. To keep internal market prices from falling below the administratively set price (set above world price levels), intervention agencies buy surpluses at the intervention price, store it, 


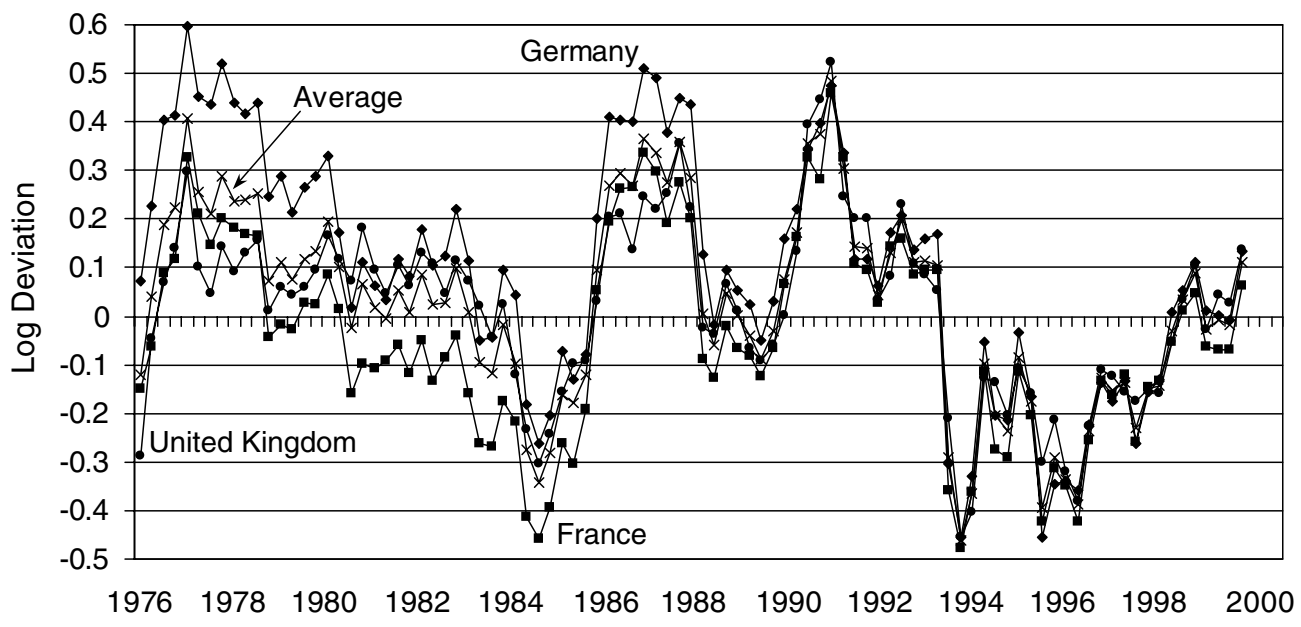

Figure 2. Deviation from LOP

and then sell on the world market at a loss, or more commonly, provide private exporters a subsidy (restitution) equal to the difference between the intervention price and the world price.

Responding to the world community demands to open its markets as well as mounting internal budgetary pressure, the CAP was reformed in 1992. The MacSharry reform is considered to be the first major structural adjustment in European agricultural policy. Implemented in July 1993, the changes were so significant to warrant the name the "new CAP" (Swinbank). Although truly significant changes occurred, they were implemented within the existing structure of variable levies, export restitutions, and the like. This structure continued to insulate European agriculture from the world economy.

Additional reform began on July 1995. At this time various changes to and disciplines of domestic agricultural policies that were agreed to under the Uruguay Round (URAA) began to be implemented. The old system of variable levies was abolished under the process of tariffication; these and other nontariff barriers were converted to conventional tariffs and reduced over time. With fixed import levies the landed price will rise and fall reflecting movements in the world price. With tariffication stronger, world price signals will be transmitted to domestic producers.

However, with the "intervention price plus $55 \%$ " rule of URAA, a de facto variable levy-type system remains at "high" reference (world price at Rotterdam) prices. Only at "low" reference prices do the fixed tariff equiv- alent rates apply and yield a landed price varying directly with the world price. ${ }^{11}$ Continued lowering of the intervention price will result in a broader range over which domestic prices will reflect world market conditions. Until that time, however, the degree of international price transmission will likely remain low (Thompson, Herrmann, and Gohout). We now test this hypothesis. ${ }^{12}$

\section{Testing and Estimation: Seeming Unrelated Regression}

\section{A Small Panel Cointegration Test}

Univariate unit root tests are imprecise. As the power of these tests is notoriously poor, nonrejection of the null hypothesis of a unit root provides little reliable information. We consider the iterative SURADF test to overcome these problems. Abuaf and Jorion; Wu; and Breuer, McNown, and Wallace use the SURADF test to investigate whether purchasing power

\footnotetext{
11 This may occur not only at low reference prices but also at high world prices. For instance, during the brief period in 1995-96 world prices were so high that the EU implemented an export tax instead of export subsidies. Due to the strength of the US\$ and the weakness of European currencies world market prices are currently also very high from an EU perspective.

${ }^{12}$ It should be noted that our main motivation for identifying dates of policy regime shifts is to investigate the degree to which three EU wheat markets are in spatial equilibrium and how liberalizing policy reforms affect the speed of adjustment to the long-run equilibrium. Certainly, the underlying wheat price time series may exhibit additional structural breaks due to reasons not mentioned above. However, a more comprehensive structural break investigation of wheat price time series is beyond the scope of this article.
} 
parity holds in the long run. Since SURADF considers the extra information of crosssectional dependence, the power of the test improves as the degree of cross-sectional correlation becomes higher. However, the asymptotic distribution of SURADF test is not known, and indeed depends on the degree of crosssectional correlation. We must construct a bootstrapped distribution to implement the SURADF test. Our statistical inferences are based on the parametric and nonparametric bootstrap. The data-generating process (DGP) underlying the bootstrap is given by

$$
\Delta q_{i t}=\sum_{j=1}^{k_{j}} \delta_{i j} \Delta q_{i t-j}+v_{i t}
$$

for $i=1,2,3$, where the contemporaneous error covariance matrix is $\Sigma=E\left(\underline{v}_{t} v_{t}^{\prime}\right)$, and $\underline{v}_{t}=$ $\left(v_{1 t}^{\prime}, v_{2 t}^{\prime}, v_{3 t}^{\prime}\right)^{\prime}$. Equation (5) asserts the null hypothesis that $q_{i t}$ is a driftless unit root process, and is fitted by iterated SUR. Details on the theoretical background of SUR and panel ECM can be found in the Appendix. The lag length $k_{j}$ is determined by the method proposed by Hall. ${ }^{13}$

With the SUR estimates in hand, the parametric bootstrap distribution for ADF $t$ is built as follows. First, we draw a sequence of length $T+100$ innovation vectors according to $\hat{v}_{i t} \sim N(0, \hat{\Sigma})$. Second, we build up the pseudoobservations $q_{i t}, i=1,2,3$ and $t=1, \ldots, T+$ 100 recursively according to equation (5) using the estimated values of the coefficients. Third, after dropping the first 100 pseudoobservations, we run the ADF regression (2) on the pseudo-data by utilizing iterated SUR and obtain the SURADF $t$-values. We do this 5,000 times, and the collection of 5,000 SURADF $t$-values forms the parametric bootstrap distribution of the test statistics from which $p$-values can be calculated.

To investigate whether the results are sensitive to the normality assumption, we also performed a nonparametric bootstrap. These distributions were built up as above except for steps 1 and 2 . In step 1 , we generate $T-\max \left\{k_{i}\right\}$ innovations by random re-sampling with replacement of the fitted residuals. In step 2 , the initial values were ob-

\footnotetext{
${ }^{13}$ Starting with $k_{j}=8$, equation (5) is estimated. If the absolute value of the $t$-ratio of the coefficient on the 8th lag is less than $1.96, k_{j}$ is reset to 7 and equation (5) is re-estimated. The process is repeated until the $t$-ratio of the estimated coefficient with the longest lag exceeds 1.96. None of the results in this article are sensitive to variations in the maximum lag $k_{j}$.
}

Table 1. Ordinary ADF Tests for the Law of One Price

\begin{tabular}{lccc}
\hline Country & ADF-t $t$ & $\begin{array}{c}p \text {-value } \\
\text { parametric } \\
\text { bootstraps) }\end{array}$ & $\begin{array}{c}p \text {-value } \\
\text { (nonparametric } \\
\text { bootstraps) }\end{array}$ \\
\hline Germany & -2.5244 & 0.1626 & 0.1454 \\
France & -2.8523 & 0.0810 & 0.0742 \\
United & -3.2074 & 0.0352 & 0.0284 \\
\multicolumn{1}{c}{ Kingdom } & & & \\
\hline
\end{tabular}

tained by block re-sampling as described by Berkowitz and Kilian. As a summary measure, we use the cross-sectional average of SURADF $t$-statistics. Im, Pesaran, and Shin (IPS) show that these average $t$-statistics have an asymptotic normal distribution as the number of cross-section components goes to infinity, $N \rightarrow \infty$.

The ordinary ADF test results for LOP of France, Germany, and the United Kingdom are reported in table 1 . The last two columns report the $p$-values for the parametric and nonparametric bootstraps, respectively; if a $p$-value is less than 0.10 , the null hypothesis of a unit root is rejected at the $10 \%$ level. The ADF $t$-value depends on the number of observations, and nuisance parameters, $\delta_{i j}$. We bootstrap the empirical distribution of ADF $t$-statistics to obtain precise $p$-values. According to the ordinary ADF test, the LOP does not hold in the long run for Germany, while it does hold for France and the United Kingdom. These results were not expected from observing the price patterns in figure 1 since the movements of wheat prices in all three countries are similar and seem to have converged toward the end of the sample.

Given the likely cross-sectional correlations among three countries depicted in figure 1, we sharpen our inference by considering a SURADF test and report these results in table 2. The SURADF yields more powerful tests and leads to the rejection of the null hypothesis of a unit root for all cases. If policy liberalization results in faster rates of convergence toward price parity, or lower values of $\rho_{i}$, then the testing results should be more favorable to LOP. To provide empirical evidence on this suggestion, we repeat the SURADF test with two additional sample periods, namely the 1976:II-1993:II period and the extended sample 1976:II-1995:II. For the sample before CAP reform, the average of ADF $t$-statistic is -1.945 and its $p$-value is around $35 \%$. As we add two more years to the sample, this 
Table 2. SURADF Tests for the Law of One Price

\begin{tabular}{lccc}
\hline Country & ADF- $t$ & $\begin{array}{c}p \text {-value } \\
\text { (parametric } \\
\text { bootstraps) }\end{array}$ & $\begin{array}{c}p \text {-value) } \\
\text { (nonparametric } \\
\text { bootstraps }\end{array}$ \\
\hline Germany & -2.6730 & 0.0890 & 0.0892 \\
France & -2.9072 & 0.0454 & 0.0438 \\
United Kingdom & -2.9248 & 0.0456 & 0.0428 \\
Average & -2.8350 & 0.0448 & 0.0418 \\
& Correlation matrix for $v_{i t}^{\text {sur }}$ & \\
Germany & Germany & France & United Kingdom \\
France & 1.0000 & 0.9510 & 0.7658 \\
United Kingdom & & 1.0000 & 0.8055 \\
Subsample (average) & & & 1.0000 \\
1976:II-1993:II & -1.945 & 0.392 & 0.340 \\
1976:II-1995:II & -2.191 & 0.269 & 0.235 \\
\hline
\end{tabular}

$t$-statistic and the corresponding $p$-value become -2.191 and around $25 \%$. Hence, the evidence for LOP becomes more favorable as more liberalized polices are implemented. ${ }^{14}$ Furthermore, for the total sample, the IPS "T-BAR" statistic also leads to the rejection of the null hypothesis. ${ }^{15}$ Thus, we conclude that LOP holds in the long run for all three countries.

\section{Error Correction Model Estimation}

Since we obtained strong evidence for LOP in the long run, we now focus on the shortrun dynamics by utilizing an ECM. The estimation results of ordinary ECM are displayed in table 3 . We consider the structural break points in the sample according to the policy regime changes described above: 1976:II1993:II, 1976:II-1995:II, 1993:III-1999:IV, and 1995:III-1999:IV. The empirical results from ordinary ECM are curious. First, the world price is expected to be exogenous, that is, not determined by domestic prices. However, all of our point estimates for $\lambda_{1 i}$ are statistically

\footnotetext{
${ }^{14}$ It should be noted that in undertaking this experiment we are interested in the long-run characteristics of the LOP. While adding more observations to a given sample increases the power of the SURADF test, a subsample investigation along the lines of our error correction estimations for the short-run dynamics would imply a decrease of power for the SURADF tests. Hence, we prefer adding observations instead of analyzing subsamples with the SURADF test.

${ }^{15}$ As an alternative to the application of the IPS "T-BAR" statistic the Bonferroni joint test can be used to conduct LOP hypothesis tests for the three countries. However, according to the findings in Maddala and $\mathrm{Wu}$, the IPS test is superior to the Bonferroni joint test, hence, the justification for our choice of the IPS "T-BAR" statistic.
}

significant. Second, none of the estimates of $\lambda_{0 i}$ are significant, which implies that domestic prices are weakly exogenous. A further unexpected result is revealed in our subsample analyses. The URAA did not affect domestic prices but did impact the world price. The point estimates for $\lambda_{0 i}$ unexpectedly become positive during the period 1995:III-1999:IV. These counterintuitive results may be due to the lack of degrees of freedom and the imprecision of the univariate analyses.

The unrestricted SURECM estimation results are reported in table 4. Contrary to the ordinary ECM estimates in table 3, the results displayed in table 4 show more intuitively reasonable findings. First, except for Germany, over the 1976:II-1993:II period, none of the estimates for $\lambda_{1 i}$ are statistically significant. This is strong evidence that the world wheat price is a weakly exogenous variable. That is, if there is a deviation from LOP, the world wheat price does not respond to eliminate this deviation. However, the estimates of $\lambda_{0 i}$ over the whole sample are significantly negative for France and Germany. This implies that domestic wheat prices force the deviation to go toward LOP.

According to the subsample analyses, CAP reforms had an effect on the convergence ratio of the deviation from LOP because the point coefficients of $\lambda_{0 i}$ became statistically significant over the sample period 1993:III-1999:IV for France and Germany. When comparing the absolute values of $\hat{\lambda}_{0 i}$ s over 1976:II-1993:II to those for 1993:III-1999:IV, the latter are larger. This implies that the convergence ratios toward LOP have become faster since the 
Table 3. Short-Run Dynamics of Ordinary ECM

$$
\begin{aligned}
& \Delta p_{i t}^{d s}=\mu_{0 i}+\lambda_{0 i} q_{i t-1}+\sum_{j=1}^{k_{j}} b 1_{i j} \Delta p_{i t-j}^{d s}+\sum_{j=1}^{l_{j}} b 2_{i j} \Delta p_{t-j}^{w}+e 1_{i t} \\
& \Delta p_{t}^{w}=\mu_{1 i}+\lambda_{1 i} q_{i t-1}+\sum_{j=1}^{k_{j}} c 1_{i j} \Delta p_{i t-j}^{d s}+\sum_{j=1}^{l_{j}} c 2_{i j} \Delta p_{t-j}^{w}+e 2_{i t}
\end{aligned}
$$

\begin{tabular}{|c|c|c|c|c|}
\hline Subsamples & Germany & France & United Kingdom & df \\
\hline \multicolumn{5}{|c|}{ The equation for $p_{i t}^{d}: \hat{\lambda}_{0 i}(\mid t$-stat $\mid)$} \\
\hline 1976:II-1999:IV & $-0.020(0.435)$ & $-0.019(0.404)$ & $-0.018(0.383)$ & 90 \\
\hline 1976:II-1993:II & $0.008(0.113)$ & $-0.018(0.281)$ & $-0.088(1.048)$ & 57 \\
\hline 1976:II-1995:II & $-0.021(0.339)$ & $-0.055(0.873)$ & $-0.092(1.373)$ & 65 \\
\hline 1993:III-1999:IV & $-0.049(0.576)$ & $-0.042(0.575)$ & $-0.024(0.400)$ & 41 \\
\hline 1995:III-1999:IV & $0.075(0.414)$ & $0.023(0.148)$ & $0.039(0.390)$ & 21 \\
\hline \multicolumn{5}{|c|}{ The equation for $p_{t}^{w}: \hat{\lambda}_{1 i}(\mid t$-stat $\mid)$} \\
\hline 1976:II-1999:IV & $0.136(3.091)$ & $0.168(3.231)$ & $0.200(3.279)$ & 90 \\
\hline 1976:II-1993:II & $0.261(4.579)$ & $0.206(3.552)$ & 0.295 (3.642) & 57 \\
\hline 1976:II-1995:II & 0.180 (3.462) & 0.183 (3.268) & $0.223(3.141)$ & 65 \\
\hline 1993:III-1999:IV & $0.158(1.816)$ & $0.166(1.804)$ & $0.188(2.043)$ & 41 \\
\hline 1995:III-1999:IV & 0.425 (2.157) & $0.514(2.380)$ & $0.487(2.353)$ & 21 \\
\hline
\end{tabular}

Note: Bold numbers denote significant coefficients at the $5 \%$ level and df the degrees of freedom.

Table 4. Short-Run Dynamics of Unrestricted SURECM

\begin{tabular}{|c|c|c|c|c|c|}
\hline Subsamples & Germany & France & United Kingdom & $x^{2}$-stat & df \\
\hline \multicolumn{6}{|c|}{ The equation for $p_{i t}^{d}: \hat{\lambda}_{0 i}(\mid t$-stat $\mid)$} \\
\hline 1976:II-1999:IV & $-0.088(2.835)$ & $-0.083(2.607)$ & $-0.050(1.243)$ & 0.951 & 272 \\
\hline 1976:II-1993:II & $-0.039(0.882)$ & $-0.055(1.328)$ & $-0.051(0.753)$ & 0.310 & 173 \\
\hline 1976:II-1995:II & $-0.049(1.284)$ & $-0.062(1.584)$ & $-0.056(1.020)$ & 0.302 & 197 \\
\hline 1993:III-1999:IV & $-0.160(2.165)$ & $-0.137(2.130)$ & $-0.083(1.442)$ & 1.526 & 125 \\
\hline 1995:III-1999:IV & $-0.180(1.293)$ & $-0.178(1.507)$ & $-0.078(0.849)$ & 0.875 & 65 \\
\hline & $1.000 \mathrm{Co}$ & $\begin{array}{c}\text { elation matrix fo } \\
0.933 \\
1.000\end{array}$ & $\begin{array}{l}0.619 \\
0.628 \\
1.000\end{array}$ & & \\
\hline \multicolumn{6}{|c|}{ The equation for $p_{t}^{w}: \hat{\lambda}_{1 i}(\mid t-$ stat $\mid)$} \\
\hline 1976:II-1999:IV & $0.013(0.889)$ & $0.015(0.880)$ & $0.017(0.826)$ & 0.112 & 272 \\
\hline 1976:II-1993:II & $0.070(2.412)$ & $0.048(1.721)$ & $0.075(1.649)$ & 2.689 & 173 \\
\hline 1976:II-1995:II & $0.033(1.412)$ & $0.032(1.323)$ & $0.038(1.055)$ & 0.046 & 197 \\
\hline 1993:III-1999:IV & $0.022(0.712)$ & $0.022(0.682)$ & $0.024(0.710)$ & 0.029 & 125 \\
\hline 1995:III-1999:IV & $0.126(1.229)$ & $0.157(1.379)$ & $0.153(1.355)$ & 0.994 & 65 \\
\hline & 1.000 Co & $\begin{array}{c}\text { elation matrix fo } \\
0.986 \\
1.000\end{array}$ & $\begin{array}{l}0.971 \\
0.977 \\
1.000\end{array}$ & & \\
\hline
\end{tabular}

$$
\begin{aligned}
& \text { (4.1) } \Delta p_{i t}^{d s}=\mu_{0 i}+\lambda_{0 i} q_{i t-1}+\sum_{j=1}^{k_{j}} b 1_{i j} \Delta p_{i t-j}^{d s}+\sum_{j=1}^{l_{j}} b 2_{i j} \Delta p_{t-j}^{w}+e 1_{i t} \\
& \text { (4.2) } \Delta p_{t}^{w}=\mu_{1 i}+\lambda_{1 i} q_{i t-1}+\sum_{j=1}^{k_{j}} c 1_{i j} \Delta p_{i t-j}^{d s}+\sum_{j=1}^{l_{j}} c 2_{i j} \Delta p_{t-j}^{w}+e 2_{i t}
\end{aligned}
$$

Note: The $5 \%$ critical value for $\chi^{2}$-stat is 5.99 and the null hypothesis is given by $\mathrm{H}_{0}: \lambda_{01}=\lambda_{02}=\lambda_{03}$. Bold numbers denote significant coefficients at the $5 \%$ level and df the degrees of freedom. 
Table 5. Short-Run Dynamics of Restricted SURECM

$$
\begin{aligned}
& \Delta p_{i t}^{d s}=\mu_{0 i}+\lambda_{0} q_{i t-1}+\sum_{j=1}^{k_{j}} b 1_{i j} \Delta p_{i t-j}^{d s}+\sum_{j=1}^{l_{j}} b 2_{i j} \Delta p_{t-j}^{w}+e 1_{i t} \\
& \Delta p_{t}^{w}=\mu_{1 i}+\lambda_{1} q_{i t-1}+\sum_{j=1}^{k_{j}} c 1_{i j} \Delta p_{i t-j}^{d s}+\sum_{j=1}^{l_{j}} c 2_{i j} \Delta p_{t-j}^{w}+e 2_{i t}
\end{aligned}
$$

\begin{tabular}{lccr}
\hline Samples & $\lambda_{0}(\mid t$-stat $\mid)$ & $\lambda_{1}(\mid t$-stat $\mid)$ & df \\
\hline 1976:II-1999:IV & $-\mathbf{0 . 0 8 0}(\mathbf{2 . 8 4 1})$ & $0.000(0.133)$ & 272 \\
1976:II-1993:II & $-0.052(1.351)$ & $0.001(0.896)$ & 173 \\
1976:II-1995:II & $-0.056(1.606)$ & $0.000(0.567)$ & 197 \\
1993:III-1999:IV & $-0.102(1.932)$ & $0.000(0.182)$ & 125 \\
1995:III-1999:IV & $-\mathbf{0 . 1 8 3}(\mathbf{2 . 1 5 7})$ & $0.001(0.429)$ & 65 \\
\hline
\end{tabular}

Note: Bold numbers denote significant coefficients at the $5 \%$ level and df the degrees of freedom.

1992 CAP reform. Further, the absolute values of $\hat{\lambda}_{0 i}$ s over 1995:III-1999:IV become larger than those for the 1993:III-1999:IV period; however, they are not statistically significant.

Overall, unrestricted SURECM provides statistically and intuitively superior point estimates than those of ordinary ECM. However, in the quest to obtain even more precise statistical inferences, we test for the homogenous restriction on $\hat{\lambda}_{0 i}$ s. The null hypothesis is $\mathrm{H}_{0}: \lambda_{01}=\lambda_{02}=\lambda_{03}$ and the test statistics are distributed $\chi^{2}$ with two degrees of freedom. When looking at the fifth column in table 4 we cannot reject the null hypothesis. Hence, we impose the homogenous restriction on the convergence ratio $\hat{\lambda}_{0 i}$, which leads us to the restricted SURECM estimation results.

The restricted SURECM findings are reported in table 5. According to our priors we find these results to be realistic and reasonable. Over the whole sample, the world wheat price is weakly exogenous since the point estimate of $\lambda_{1}$ is not significantly different from zero. On the other hand, domestic wheat prices are endogenous, which implies that domestic wheat prices have adjusted to eliminate the deviation from LOP. Since the world wheat price is documented to be weakly exogenous, the point estimate of $\hat{\lambda}_{0}$ conveys other valuable information. That is, the half-life of the deviation from LOP, $\hat{\lambda}_{0}=0.08$, is about two years. In other words, if the world price increases by $\$ 1$, then domestic prices can be expected to increase by $\$ 0.5$ within two years $[(\ln (0.5) / \ln (1.0$ $0.8)) / 4.00=2]$.

According to our subsample analyses, CAP reform (MacSharry), as well as the URAA, have reduced trade barriers among wheat markets and increased the transmission of world wheat prices to domestic markets. After the 1992 CAP reform was implemented in July 1993, $\hat{\lambda}_{0}$ becomes -0.102 and statistically significant at the $10 \%$ level. After URAA, $\hat{\lambda}_{0}$ increases to -0.183 and is significant even at the $5 \%$ level. ${ }^{16}$ Our wheat price transmission elasticity estimate of 0.183 is substantially lower than the 0.72 reported by Mundlak and Larson for the EU, but very close to the more recent estimates of Thompson, Herrmann, and Gohout. These latter authors demonstrated theoretically that even under the "new CAP," price transmission elasticities should be near zero. Using world and German wheat market data (1976-98), they obtained price transmission elasticities of 0.11 to 0.13 . Thus, our results are consistent with both theoretical expectations and also previous findings. Furthermore, the half-life was reduced further to 1.6 and 0.9 years as a result of the MacSharry and URAA regimes, respectively. Even though these half-life values showed improved wheat market efficiency due to market liberalizing policy changes, they do not suggest perfect market integration. The "intervention price plus 55\%" rule of the URAA and other policy rigidities continue to restrain progress toward fully integrated spatial wheat markets.

\section{Concluding Remarks}

In this article, we investigate the degree to which three EU wheat markets are in spatial

\footnotetext{
${ }^{16}$ Since $q_{i t}=p_{i t}^{d s}-p_{t}^{w}$, a negative value for $\hat{\lambda}_{0}$ implies a positive price transmission elasticity.
} 
equilibrium and how policy reforms affect the speed of adjustment to the long-run relationship. We introduce a statistical procedure that is appropriate when estimating a system of equations that bear a close conceptual relationship with one another. Seemingly unrelated cointegration tests SURADF and error correction models SURECM are used to test whether the LOP holds, and to examine the short-run adjustment dynamics. The SURADF and SURECM estimates are compared to ordinary ADF and ECM models and the results were found to be remarkably different. The statistical efficiency gains attributable to the information contained in the error covariance matrix are illustrated.

In contrast to the ordinary ADF tests, applying SURADF we found the LOP to hold in all three markets. Since the asymptotic distribution of SURADF is not known, we built parametric and nonparametric bootstrap distributions of the test statistic. Accordingly, the empirical support for the existence of the LOP is highly reliable.

Since we obtained strong evidence for LOP in the long run we next utilized an ECM to investigate the short-run price adjustment dynamics. Once again, we found the SURECM method to yield more economically sensible parameter estimates than ordinary ECM methods. Finally, we tested for the homogeneity restriction on the parameters among the three wheat markets and found that we could not reject the homogeneity restriction. Estimates for our restricted SURECM over the periods of market liberalization reforms showed increased domestic-world wheat price comovement and price convergence as policy reforms developed. In particular, subsequent to the 1992 MacSharry reforms, a statistically significant price transmission elasticity of 0.102 (half-life of 1.6 years) was estimated. This elasticity estimate was nearly double that obtained during the "old CAP" policy regime. Moreover, with the implementation of the URAA reforms, we found the price transmission elasticity to increase to 0.183 (half-life 0.9 years). Using improved statistical procedures we found that EU wheat markets are in spatial market equilibrium and that policyliberalizing reforms contribute to a more rapid convergence of domestic and international prices.

\section{[Received October 2000; final revision} received October 2001.]

\section{References}

Abuaf, N., and P. Jorion. "Purchasing Power Parity in the Long Run." J. Fin. 45(1990):157-74.

Ardini, P.G. "Does the Law of One Price Really Hold for Commodity Prices?" Amer. J. Agr. Econ. 71(August 1989):661-69.

Baffes, J. "Some Further Evidence on the Law of One Price: The Law of One Price Still Holds." Amer. J. Agr. Econ. 73(November 1991):126493.

Barrett, C.B. "Measuring Integration and Efficiency in International Agricultural Markets." Rev. Agr. Econ. 23(Spring/Summer 2001):19-32.

Blauch, B. "Transfer Costs, Spatial Arbitrage, and Testing for Food Market Integration." Amer. J. Agr. Econ. 79(May 1997): 447-78.

Berkowitz, J., and L. Kilian. "Recent Developments in Bootstrapping Time Series." Econometric Rev. 19(February 2000):1-54.

Breuer, J.B., R. McNown, and M. Wallace. "The Quest for Purchasing Power Parity with a Series-specific Test Using Panel Data." Mimeo, University of South Carolina, 2000.

Engle, R.F., and C.W.J. Granger. "Co-integration and Error Correction: Representation, Estimation, and Testing." Econometrica 55(March 1987):251-76.

Fackler, P.L., and B.K. Goodwin. "Spatial Market Integration." Handbook of Agricultural Economics. G. Rausser and B. Gardner, eds. Amsterdam: Elsevier Publishing, 2001.

Hakkio, C.S., and M. Rush. "Cointegration: How Short is The Long Run?" J. Int. Mon. Fin. 10(1991):571-81.

Hall, A. "Testing for a Unit Root in Time Series with Pretest Data-Based Model Selection." J. Bus. Econ. Stat. 12(1994):461-70.

Im, K.S., M.H. Pesaran, and Y. Shin. "Testing for Unit Roots in Heterogeneous Panels." Discussion Paper, University of Cambridge, 1997.

Goodwin, B.K., and N.E. Piggott. "Spatial Market Integration in the Presence of Threshold Effects." Amer. J. Agr. Econ. 83(May 2001):302-17.

Maddala, G.S., and S. Wu. "A Comparative Study of Unit Root Tests with Panel Data and a New Simple Test." Oxf. Bull. Econ. Stat. 61(November 1999):631-52.

Mark, N.C., M. Ogaki, and D. Sul. "Dynamic Seemingly Unrelated Cointegrating Regression." Working Paper, The Ohio State University, 2000.

McNew, K., and P. Fackler. "Testing Market Equilibrium: Is Cointegration Informative?" $J$. Agr. Resour. Econ. 22(December 1997):191207. 
Miljkovic, D. "The Law of One Price in International Trade: A Critical Review." Rev. Agr. Econ. 21(Spring/Summer 1999):126-39.

Mundlak, Y., and D.F. Larson. "On the Transmission of World Agricultural Prices." World Bank Econ. Rev. 6(September 1992):399_ 422.

Swinbank, A. "The New CAP." The Common Agricultural Policy. C. Ritson and D.R. Harvey, eds. London: CAB International, 1997.

Thompson, S.R., R. Herrmann, and W. Gohout. "Agricultural Market Liberalization and Instability of Domestic Agricultural Markets: The Case of the CAP." Amer. J. Agr. Econ. 82(August 2000):718-26.

von Cramon-Taubadel, S., J.-P. Loy, and E. Musfeldt. "Empirische Methoden zur Analyse der Marktintegration am Beispiel des EUSchweinefleischmarktes." Tagungsband der 35. Jahrestagung der Gesellschaft für Wirtschaftsund Sozialwissenschaften des Landbaus e.V. (October 1994):119-37.

Wu, Y. "Are Real Exchange Rates Nonstationary? Evidence from Panel Data Tests." J. Money, Credit, and Banking 28(1998):54-63.

Zanias, G.P. "Seasonality and Spatial Integration in Agricultural (Product) Markets." Agr. Econ. 20(May 1999):253-62.

\section{Appendix}

\section{SUR and Panel ECM}

In this appendix, we provide the theoretical background of SUR and panel ECM. As a starting point we assume a cointegrating relationship between the two individually integrated times series, $x_{t}$ and $y_{t}$, so that the linear combination $y_{t}-\lambda x_{t}=q_{t}$ follows a stationary process with the cointegrating parameter $\lambda$. According to the Granger representation theorem (Engle and Granger) there exists a valid error correction representation given by

$$
\begin{aligned}
\Delta y_{t}= & \alpha_{y}+\beta_{y}\left(y_{t-1}-\lambda x_{t-1}\right) \\
& +\sum_{i=1}^{p} \delta_{1 i}^{y} \Delta y_{t-i}+\sum_{i=1}^{p} \delta_{1 i}^{x} \Delta x_{t-i}+\varepsilon_{y t}
\end{aligned}
$$

and

(A.2) $\Delta x_{t}=\alpha_{x}+\beta_{x}\left(y_{t-1}-\lambda x_{t-1}\right)$

$$
+\sum_{i=1}^{p} \delta_{2 i}^{y} \Delta y_{t-i}+\sum_{i=1}^{p} \delta_{2 i}^{x} \Delta x_{t-i}+\varepsilon_{x t} .
$$

Under the assumption $\lambda=1$, we denote $q_{t}=y_{t}-x_{t}$. Since $\Delta y_{t}$ and $\Delta x_{t}$ in equations (A.1) and (A.2) have exactly the same explanatory variables, there is no efficiency gain for SUR even when there is perfect correlation between $\varepsilon_{y t}$ and $\varepsilon_{x t}$.

However, an efficiency gain can be obtained over cross-sectional units. Consider the case of two crosssectional units, $q_{1 t}=x_{1 t}-y_{1 t}$ and $q_{2 t}=x_{2 t}-y_{2 t}$. There is no efficiency gain for SUR if one does SUR over $x_{i t}$ and $y_{i t}$ for each $i$. However, as long as $x_{1 t}$ is highly correlated with $x_{2 t}$, efficiency gain is possible. Consider

$$
\begin{aligned}
\Delta x_{1 t}= & \alpha_{1}^{x}+\beta_{1}^{x} q_{1 t-1}+\delta_{11}^{y}(L) \Delta y_{1 t} \\
& +\delta_{11}^{x}(L) \Delta x_{1 t}+\varepsilon_{x 1 t} \\
\Delta x_{2 t}= & \alpha_{2}^{x}+\beta_{2}^{x} q_{2 t-1}+\delta_{12}^{y}(L) \Delta y_{2 t} \\
& +\delta_{12}^{x}(L) \Delta x_{2 t}+\varepsilon_{x 2 t}
\end{aligned}
$$

where the explanatory variables differ over $i$. As there is higher cross-sectional correlation between $\varepsilon_{x 1 t}$ and $\varepsilon_{x 2 t}$, and there is less cross-sectional correlation among explanatory variables in the system, a more efficient estimator of $\beta_{i}^{x}$ can be obtained. Similarly, the second system of SURECM for $\Delta y_{i t}$ can be given by

$$
\begin{aligned}
\Delta y_{1 t}= & \alpha_{1}^{y}+\beta_{1}^{y} q_{1 t-1}+\delta_{21}^{y}(L) \Delta y_{1 t} \\
& +\delta_{21}^{x}(L) \Delta x_{1 t}+\varepsilon_{y 1 t} \\
\Delta y_{2 t}= & \alpha_{2}^{y}+\beta_{2}^{y} q_{2 t-1}+\delta_{22}^{y}(L) \Delta y_{2 t} \\
& +\delta_{22}^{x}(L) \Delta x_{2 t}+\varepsilon_{y 2 t} .
\end{aligned}
$$

The degree of efficiency gain depends on the degrees of cross-sectional correlation between $\varepsilon_{y 1 t}$ and $\varepsilon_{y 2 t}$. However, it will be inefficient, if all four equations are estimated by SUR for two reasons. First, the ECM system for $i=1$, that is (A.3) and (A.5), has exactly the same explanatory variables so that there is no efficiency gain over these two first equations. This same argument can be applied for the ECM system for $i=2$. Second, $\varepsilon_{y 1 t}$ may be correlated with $\varepsilon_{x 2 t}$. However, if this correlation between $\varepsilon_{y 1 t}$ and $\varepsilon_{x 2 t}$ is much lower than that between $\varepsilon_{y 1 t}$ and $\varepsilon_{y 2 t}$, or that between $\varepsilon_{x 1 t}$ and $\varepsilon_{x 2 t}$, the inclusion of the second system into the first system provides less-efficient estimators.

Denote the covariance and variance matrix of $\varepsilon_{x t}=\left(\varepsilon_{x 1 t}^{\prime}, \varepsilon_{x 2 t^{\prime}}^{\prime}\right.$ as $\Sigma_{\varepsilon}$ and let $\sigma_{i j}$ be the $i$ th and $j$ th element of the matrix $\Sigma_{\varepsilon}^{-1}$. Then the SUR estimators $\beta^{x}=\left(\beta_{1}^{x}, \beta_{2}^{x}\right)^{\prime}$ in the first system are given by

$$
\begin{aligned}
\hat{\beta}^{x}= & {\left[\begin{array}{ll}
\sigma_{11} W_{1}^{\prime} W_{1} & \sigma_{12} W_{1}^{\prime} W_{2} \\
\sigma_{12} W_{2}^{\prime} W_{1} & \sigma_{22} W_{2}^{\prime} W_{2}
\end{array}\right]^{-1} } \\
& \times\left[\begin{array}{l}
\sum_{i=1}^{2} \sigma_{1 i} W_{i}^{\prime} \Delta x_{i t} \\
\sum_{i=1}^{2} \sigma_{2 i} W_{i}^{\prime} \Delta x_{i t}
\end{array}\right]
\end{aligned}
$$

where $W_{1}$ and $W_{2}$ are vectors of explanatory variables in equations (A.3) and (A.4), respectively. 
Testing homogeneity of $\beta \mathrm{s}, \mathrm{H}_{0}: \beta_{1}^{x}=\beta_{2}^{x}$, can be directly implemented by

$$
\text { (A.8) } J=\left(R \hat{\beta}^{x}-r\right)^{\prime}
$$

$$
\begin{aligned}
& \times\left[R\left[\begin{array}{ll}
\sigma_{11} W_{1}^{\prime} W_{1} & \sigma_{12} W_{1}^{\prime} W_{2} \\
\sigma_{12} W_{2}^{\prime} W_{1} & \sigma_{22} W_{2}^{\prime} W_{2}
\end{array}\right]^{-1} R^{\prime}\right]^{-1} \\
& \times\left(R \hat{\beta}^{x}-r\right) \rightarrow \chi^{2}(1)
\end{aligned}
$$

where $R=(1,-1)$ and $r=0$. Once the homogeneity restriction is not rejected, the more efficient estimator can be constructed through pooling the system regressions together. That is,

(A.9) $\quad \Delta x_{1 t}=\alpha_{1}^{x}+\beta_{*}^{x} q_{1 t-1}+\delta_{11}^{y}(L) \Delta y_{1 t}$

$$
+\delta_{11}^{x}(L) \Delta x_{1 t}+\varepsilon_{x 1 t}
$$

(A.10) $\Delta x_{2 t}=\alpha_{2}^{x}+\beta_{*}^{x} q_{2 t-1}+\delta_{12}^{y}(L) \Delta y_{2 t}$

$$
+\delta_{12}^{x}(L) \Delta x_{2 t}+\varepsilon_{x 2 t} \text {. }
$$

Since there is correlation between two regression residuals, a pooled OLS estimator is not efficient. However, a panel feasible generalized least-squares estimator can restore the efficiency which is given by

(A.11) $\hat{\beta}_{p f g l s}^{x}=\left(W^{\prime} \hat{\Sigma}_{\varepsilon}^{-1} W\right)^{-1}\left(W^{\prime} \hat{\Sigma}_{\varepsilon}^{-1} \Delta x\right)$

where $W=\left(W_{1}^{\prime}, W_{2}^{\prime}\right)^{\prime}, \hat{\Sigma}_{\varepsilon}=\frac{1}{T-k} \sum \hat{\varepsilon}_{x t}^{\prime} \hat{\varepsilon}_{x t}, \hat{\varepsilon}_{x}=\left(\varepsilon_{x 1 t}^{\prime}\right.$, $\left.\varepsilon_{x 2 t}^{\prime}\right)^{\prime}$, and $k$ is the number of regressors. Mark, Ogaki, and Sul provide the theoretical reasoning why SUR cointegrating system becomes more efficient and useful in practice. 
Copyright $\odot 2002$ EBSCO Publishing 